\title{
Inheritance of Phenological, Vegetative, and Fruit Chemistry Traits in Black Raspberry
}

\author{
Michael Dossett \\ Department of Horticulture, Oregon State University, $4017 \mathrm{Ag}$ and Life Sciences Building, \\ Corvallis, OR 97331-7304
}

Jungmin Lee

U.S. Department of Agriculture, Agricultural Research Service, Horticultural Crops Research Unit worksite, Parma, ID 83660

Chad E. Finn' ${ }^{1}$

U.S. Department of Agriculture, Agricultural Research Service, Horticultural Crops Research Unit, 3420 NW Orchard Avenue, Corvallis, OR 97330

\begin{abstract}
AdDitional INDEX words. Rubus occidentalis, blackcap, diallel, GCA, SCA, heritability, phenolics, anthocyanins, pigment, color

Abstract. In recent years, there has been renewed interest in black raspberry (Rubus occidentalis L.) breeding. This has been spurred by an increase in black raspberry consumption resulting from studies that have shown them to be particularly high in anthocyanin content indicating high levels of antioxidants. Present cultivars are ill-adapted to the biotic and abiotic stresses of the Pacific northwestern United States, where the commercial black raspberry industry is centered, and fields must be replanted after three to five seasons. An incomplete partial diallel, consisting of 10 parents and 26 sibling families, was constructed for the study of variation and inheritance of phenological, vegetative, and fruit chemistry traits in black raspberry. Sibling families were established at the Oregon State University Lewis Brown Farm in Corvallis and were arranged as a randomized complete block design with four blocks of one to eight plants. Phenological development and vegetative measurements were recorded for each plant in 2005 and 2006. In addition, 25-berry samples of ripe fruit were collected from each plant. To study variation in fruit chemistry properties, including $\mathrm{pH}$, titratable acidity, percent soluble solids, anthocyanin profiles, and total anthocyanins, additional samples of 25 ripe berries were collected from each plant and pooled by family within blocks. Although there were many striking similarities, strong trends in phenotype based on pedigree were observed for most traits indicating a strong genetic component. General combining ability (GCA) effects were significant and larger than specific combining ability effects for all traits, except for fruit size (mass). With the exception of fruit size, narrow-sense heritability estimates were generally moderate to high $(0.30$ to 0.91$)$, indicating the potential for breeding progress within the population of plants studied. Despite these results, statistically significant and large GCA values were limited to just a few of the parents, indicating a lack of heritable genetic variation in much of the germplasm base and a need for greater diversity.
\end{abstract}

Interest in the anthocyanin pigments of black raspberry is not limited to recent studies showing their potential health benefits. Black raspberry has a long history of use not only in jams and other processed products, but also as a natural colorant/dye because of its high anthocyanin levels. Research on the anthocyanin pigments and fruit chemistry properties of black raspberries, and other Rubus L. fruit, dates back at least to the 1950s. Lee and Slate (1954) examined some of the chemical properties of three cultivars to understand what differences made some better than others for freezing or use in other processed products. However, since the early 1900s, black raspberry production in the United States has seen a marked decline that many attribute to disease pressures and a lack of cultivars with sufficient resistance. At the same time, breeding progress has slowed dramatically as a result of an apparent lack of

Received for publication 7 Dec. 2007. Accepted for publication 26 Feb. 2008. This project was supported by a grant from the USDA-ARS Northwest Center for Small Fruits Research.

We thank Mary Peterson, Chris Rennaker, Brian Yorgey, and Tim Righetti for their contributions to this project.

${ }^{1}$ Corresponding author. E-mail: chad.finn@ars.usda.gov. genetic variability in available elite germplasm (Ourecky, 1975). Despite successes and progress in the early years of black raspberry germplasm improvement, Ourecky (1975) considered a lack of genetic diversity in black raspberry to be a major limitation for breeding. He found it nearly impossible to distinguish existing cultivars from each other and said that no future progress would be made in black raspberry breeding without the use of germplasm from other species. These limitations have been recognized by many over the last century and attempts to use other species to introduce desirable traits to black raspberry have been made (Drain, 1956; Ourecky and Slate, 1966; Slate and Klein, 1952). However, there is no record of interspecific hybridization leading to any new cultivars until the release of 'Earlysweet' in 1996, which has Rubus leucodermis Douglas ex Torr. \& A. Gray in its background (Galletta et al., 1998).

Weber (2003) examined genetic diversity in R. occidentalis using random amplified polymorphic DNA (RAPD) markers. RAPD markers were scored in 14 cultivars and two wild selections and as a whole showed $81 \%$ similarity in polymorphic markers. More than half of this variability was accounted for by 'Black Hawk', 'Cumberland', 'John Robertson', and the two 
wild selections from New York. The remaining 11 genotypes in this study had a collective marker similarity of $92 \%$. Weber asserted that this supports the idea that many cultivars that originated as chance seedlings were probably from openpollinated fruit of previously named selections. Nybom and Schaal (1990) used restriction fragment length polymorphisms to document genetic diversity in wild black raspberries along a $600-\mathrm{m}$ stretch of roadside in Missouri and found 15 unique genotypes among 20 plants sampled. These results suggest that there may be a great deal more genetic diversity in wild populations than in current cultivars.

Although the level of genetic diversity in black raspberry cultivars has been well documented (Weber, 2003), studies regarding the degree and heritability of phenotypic variation are lacking. In addition, previous research and breeding efforts have been focused in the eastern United States, whereas commercial production is centered in Oregon. At present, the black raspberry processing industry is entirely reliant on a single cultivar, Munger, developed and released in the 1890s (Hedrick, 1925). 'Munger' has served the industry surprisingly well, but growers are experiencing increasing problems resulting from high disease pressure from Verticillium wilt (Verticillium albo-atrum Reinke \& Berthier), anthracnose [Elsinoe veneta (Burkholder) Jenk.], and a number of viruses affecting yield and longevity of plantings. The yield, which has averaged only $2845 \mathrm{~kg} \cdot \mathrm{ha} \mathrm{a}^{-1}$ over the past 5 years, is low and needs to be increased for production to remain economically viable (U.S. Department of Agriculture, 2007a). In addition, the average life of a planting is only three or four growing seasons (Halgren et al., 2007). This is a drop from an average of seven cropping seasons, over 50 years ago, on 36 farms surveyed by Kuhlman and Mumford (1949) who noted that the life of plantings historically had been even longer than their survey showed.

Although the four major anthocyanins found in black raspberry have been known for many years (Barritt and Torre, 1973; Harborne and Hall, 1964; Nybom, 1968; Torre and Barritt, 1977), recent studies using high-performance liquid chromatography (HPLC) and mass spectrometry (MS) have identified a wider range of pigments in the fruit than was previously known. Although these studies did not identify the genotypes that their samples came from, small amounts of three anthocyanins, pelargonidin-3-rutinoside, pelargonidin-3-glucoside, and peonidin-3-rutinoside, which had not been previously identified in black raspberry, were detected (Tian et al., 2006; Wu and Prior, 2005). Other work has shown black raspberries to be particularly high in total anthocyanin (TACY) content as well as total phenolics (TP) and antioxidant capacity (Moyer et al., 2002; Wang and Lin, 2000). Although there is a great deal of new research in the antioxidant properties of black raspberries, there is still very little known about genotypic differences and heritability for these traits. Heritability of anthocyanins, total phenolics, and antioxidant properties have been studied in red raspberry (Rubus idaeus L.) (Connor et al., 2005a, 2005b), but similar studies for black raspberry are lacking.

New cultivars, which are adapted to the biotic and abiotic stresses of the Pacific northwestern United States, may help expand the market and improve the financial return to growers. However, to develop these cultivars, it is essential to gain a basic understanding of the feasibility of selecting and breeding for the traits of interest from the variation present in available germplasm. The objectives of this study are to gain insight into the performance of black raspberry genotypes as parents in the development of new cultivars adapted to the Pacific northwestern United States and to gain an understanding of the variation present in available genotypes for general plant performance and important fruit chemistry traits. Estimating the quantitative genetic parameters involved in these traits will allow us to determine whether there is a need for greater genetic diversity and the potential for progress from selection in breeding new cultivars with improved traits as well as help us to use the available parents more efficiently in the breeding program.

\section{Materials and Methods}

Field Planting and maintenance. Crosses between 'Black Hawk', 'Dundee', 'Hanover', 'Jewel', 'John Robertson', 'Mac Black', 'Munger', and 'New Logan' as well as a wild selection of $R$. occidentalis (NC 84-10-3; PI 553755) and a bulk pollen sample from $R$. leucodermis were performed in 2002 in an incomplete partial diallel mating scheme (Table 1). NC 84-10-3 was selected from seed collected by J.R. Ballington (North Carolina State University, Raleigh) from wild plants in the Piedmont-Coastal Plain of North Carolina and was provided by the U.S. Department of Agriculture-Agricultural Research Service, National Clonal Germplasm Repository, in Corvallis, OR (U.S. Department of Agriculture, 2007b). The original selection was made in an effort to identify resistance to heat and fungal diseases. The pollen sample from $R$. leucodermis came from populations selected from Oregon and Washington (Finn et al., 2003). The cultivars used as parents were chosen as the best performers during evaluations in the late 1990s of all

Table 1. Partial diallel mating scheme and parentage for 26 black raspberry families for crosses made in 2002.

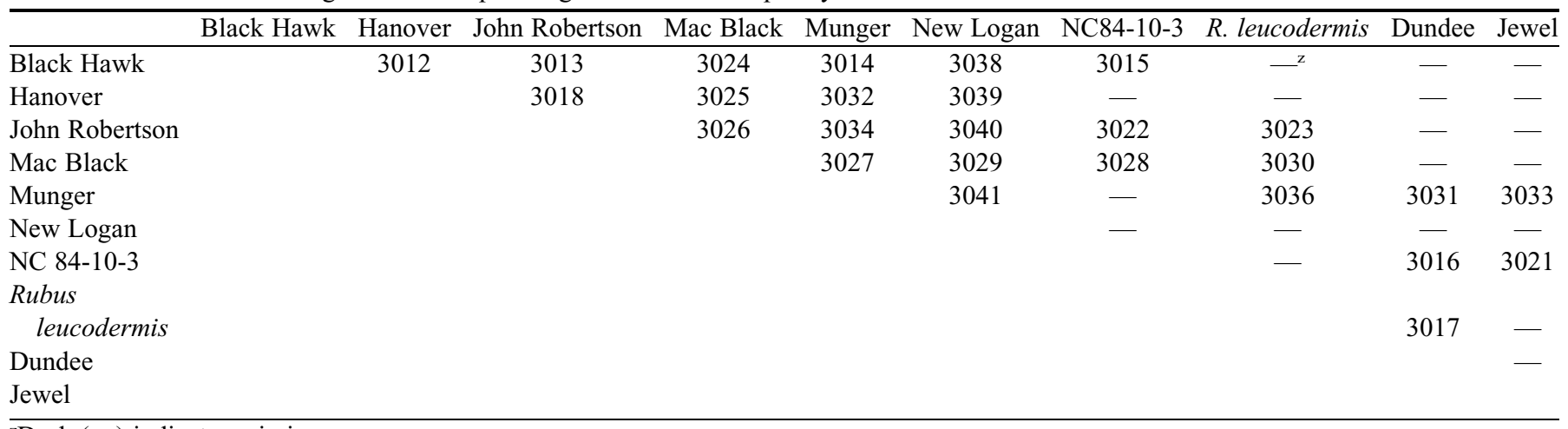

${ }^{\mathrm{z}}$ Dash (-) indicates missing crosses. 
available black raspberry cultivars at the Oregon State University (OSU) North Willamette Research and Extension Center at Aurora. Information regarding the pedigrees and geographic origins of the cultivars used as parents is limited and complicated by the fact that many were discovered as chance seedlings near commercial fields of cultivars originating in other regions. Seedlings were planted in the field in Summer 2003 in a randomized complete block design with four replications of 26 sibling families at the OSU Lewis Brown Farm in Corvallis, OR. Plants were spaced $0.91 \mathrm{~m}$ apart on raised beds in rows spaced $2.74 \mathrm{~m}$ apart. Sibling families consisted of one to eight plants in each replication depending on the number of available seedlings. The field was maintained by standard commercial practices with regard to fertilization, weed control, and irrigation. Plants were trained to a three-wire trellis system with a lower wire at $0.50 \mathrm{~m}$ and two parallel wires hung $0.15 \mathrm{~m}$ apart at $0.91 \mathrm{~m}$. Primocanes were trained between the parallel wires and primocane tips were removed at $\approx 1 \mathrm{~m}$ to induce branching in early June, a few weeks before fruit ripening. In the fall, primocane branches were pruned near the tips to help prevent them from rooting in the row. Floricanes from the previous fruiting season were removed, whereas plants were dormant in Winter 2004 to 2005 and again in Fall 2005. In late winter, new floricanes were pruned so that floricane branches were $\approx 30 \mathrm{~cm}$ in length.

COLlECTION OF FIELD DATA AND FRUIT SAMPLES. In 2005 and 2006 , dates of budbreak $(\approx 3 \mathrm{~mm}$ green seen protruding from bud tips), first bloom (first fully open flower), and fruit ripening (first fully colored fruit) were recorded for each plant. In addition, each plant was rated on a 1 to 9 scale $(1=$ very poor vigor, $9=$ extremely vigorous) scale for primocane vigor in the spring and again in late summer of both years. Incidences (presence or absence) of powdery mildew [Sphaerotheca macularis (Wallr.:Fr.) Lind.], anthracnose, and Verticillium wilt were recorded by visual inspection in both years and, in 2005, all plants were tested by enzyme-linked immunosorbent assay (ELISA) for incidence of raspberry bushy dwarf virus (RBDV), tobacco streak virus (TSV), and tomato ringspot virus (TomRSV). In Spring 2006 and 2007, plants were scored for the amount of cane death over the winter $(0=$ no floricane death or injury to cane tips, $5=80 \%$ to $100 \%$ of floricanes dead). The number of nodes below the terminals of fruiting laterals at which fruit was present was recorded in both years by taking an average count of 10 random laterals from each plant. Samples of 25 nonprimary fruit were collected during midseason from terminal clusters on each plant for weighing and further analysis. In a few cases, 25 ripe fruit were not available from a given plant so all available ripe fruit were collected and the berry count recorded. Harvested samples were cooled in an ice chest containing ice packs and immediately frozen $\left(-23{ }^{\circ} \mathrm{C}\right)$ after arrival at the laboratory. Samples harvested for measuring fruit size (mass) were thawed and then weighed. Care was taken to account for juice loss and condensation during the weighing process.

Fruit sampling, SAMple preparation, percent soluble SOlids, PH, AND TITRATABle ACIDITY. A second sample of 25 berries from each plant was collected for fruit chemistry analysis. These samples were bulked by population within each block and an entire block was picked in a single day to minimize variation from the effects of differing irrigation status and weather at harvest. Berry samples collected for fruit chemistry analysis were picked when they were ripe as determined by being fully colored and separating readily from the receptacle but not overripe or shriveled on the plant. Harvested fruit were treated as described in the previous section. Bulked samples for fruit chemistry analysis were thawed at $1{ }^{\circ} \mathrm{C}$ for $24 \mathrm{~h}$ before being puréed in a blender for $1 \mathrm{~min}$. An aliquot of the puréed sample was then centrifuged at room temperature at $3446 g_{n}$ for $10 \mathrm{~min}$ to separate the juice from the pulp. The supernatant was then refrozen at $-23{ }^{\circ} \mathrm{C}$ for later use in measuring percent soluble solids, TACY, and TP. The remaining puréed portion of the sample was used for measuring $\mathrm{pH}$ and titratable acidity (TA). Five grams of purée were diluted with $45 \mathrm{~mL}$ of $\mathrm{CO}_{2}$ free water and titrated with 0.1 $\mathrm{N} \mathrm{NaOH}$ to a $\mathrm{pH} 8.1$ end point using a Mettler DL 12 Titrator (Mettler-Toledo, Columbus, OH). TA was replicated two times and was expressed as citric acid equivalents (grams per $100 \mathrm{~g}$ of berries). Percent soluble solids of the juice was determined by a RFM 81 automatic refractometer (Bellingham and Stanley, Lawrenceville, GA) and was temperature-compensated.

TOTAL PHENOLICS AND TOTAL ANTHOCYANIN DETERMINATION BY ABSORBANCE. Determination of TP was performed using the Folin-Ciocalteu method as described by Waterhouse (2002) and TACY was performed using the $\mathrm{pH}$ differential method described by Lee et al. (2005). Plates (clear, flat-bottomed 96well plate; Nalge Nunc Intl., Rochester, NY) containing reaction mixtures were read for absorbance at 765 (for TP), 520 , and $700 \mathrm{~nm}$ (for TACY) on a SpectraMax M2 microplate reader (Molecular Devices, Sunnyvale, CA). TP were expressed as gallic acid equivalents. TACY was expressed as cyanidin-3-glucoside (molar extinction coefficient $=26,900$ $\mathrm{L} \cdot \mathrm{cm}^{-1} \cdot \mathrm{mol}^{-1}$, molecular weight $\left.=449.2 \mathrm{~g} \cdot \mathrm{mol}^{-1}\right)$. Each sample was run in duplicate and the results averaged.

Anthocyanin anAlysis By high-PERFormance LiQUid CHROMATOGRAPHY. TACY was also determined separately by HPLC by adding together the total amounts of the individual anthocyanins outlined subsequently. Juice samples for HPLC anthocyanin analysis were filtered with a $0.45-\mu \mathrm{m}$ syringedriven polytetrafluoroethylene filter (Millipore, Bedford, MA). Anthocyanin profiles were determined by HPLC/diode array detector/ion trap mass spectrometer (HPLC/DAD/ESI-MS/ MS) on an Agilent 1100 series system (Agilent Technologies, Santa Clara, CA). The analytical column, mobile phase composition, and the gradient program used for HPLC analysis are described by Lee and Finn (2007). Sample injection volume was $5 \mu \mathrm{L}$. Anthocyanins were monitored at $520 \mathrm{~nm}$ and quantified with a cyanidin-3-glucoside standard (Polyphenol As, Sandnes, Norway). Ultraviolet-visible (UV-Vis) absorption spectra (190 to $600 \mathrm{~nm}$ ) were collected for all peaks. ESI-MS/ MS parameters were set as described in Lee and Finn (2007). Individual peak assignments were made according to UV-Vis spectra, retention times, molecular ions mass-to-charge ratio $(\mathrm{m} / \mathrm{z})$, and fragmented ions $\mathrm{m} / \mathrm{z}$.

DAta ANALYSis. Statistical analyses were performed using SAS (version 9.1; SAS Institute, Cary, NC). Analyses of variance were conducted using the SAS PROC GLM procedure for analysis of family means. Calculations for general combining ability (GCA) and specific combining ability (SCA) were performed as outlined by Griffing (1956) for a half-diallel mating scheme with no reciprocals and with parents treated as fixed effects (Method 4, Model 1). To do this analysis, crosses involving the parents 'Dundee' and 'Jewel' were removed from the data set, thereby removing 12 missing crosses and ensuring that at least two parents ('John Robertson' and 'Mac Black') 
had no missing crosses. The program DIAFIXED.SAS (Wu and Matheson, 2000) was used to generate a design matrix and perform GCA and SCA calculations using a least squares correction for the missing crosses. Removal of the parents 'Dundee' and 'Jewel' from the analysis not only removed the fewest number of crosses (five) from the diallel to meet the requirements of the design matrix, but also made the most logical sense because they are closely related and 'Jewel' has a high level of inbreeding (Jennings, 1988). Although no genetic assumptions are required when interpreting combining ability effects using this analysis, to make assertions about heritability of the traits in question, it was assumed that there were no epistasis effects, that alleles were evenly distributed among the parents, and that parents had the same level of inbreeding.

Narrow-sense heritability $\left(h^{2}\right)$ estimates were calculated based on the appropriate mean square terms from the GCA/ SCA analysis. Contributions of the genetic components were calculated from variance components in the same manner as Geleta and Labuschagne (2006) where $h^{2}=\sigma_{\mathrm{a}}{ }^{2} / \sigma_{\mathrm{p}}{ }^{2}$ and where $\sigma_{\mathrm{a}}^{2}=2\left(\sigma_{\mathrm{gca}}{ }^{2}\right)$. The $\sigma_{\mathrm{gca}}{ }^{2}$ is derived from the expected value of the mean square for GCA. A term for missing crosses was included by using the average number of crosses per parent (5.25) as shown by Kempthorne and Curnow (1961). For the analyses, years were treated as separate environments. Because year $\times$ GCA and SCA interactions were not significant $(P \geq$ 0.2 ) for all traits except fruiting nodes, flowering, and ripening times, the data were analyzed with these terms excluded from the model and heritability calculations except for these traits. The linear model for the cross $i \times j$ in block $l$ in year $q$ can thus be written as:

$$
\mathrm{Y}_{\mathrm{ijlq}}=\mu+\mathrm{b}_{1}+\mathrm{k}_{\mathrm{q}}+\mathrm{g}_{\mathrm{i}}+\mathrm{g}_{\mathrm{j}}+\mathrm{s}_{\mathrm{ij}}+\mathrm{e}_{\mathrm{ijlq}}
$$

where $\mu$ is the grand mean, $b_{1}$ is the block effect, $k_{q}$ is the year effect, $g_{i}$ and $g_{j}$ are GCA effects, $s_{i j}$ is the SCA effect, and $e_{i j l q}$ is the term for plot error. When analyzing the percentage of the total for individual anthocyanins, the inverse of TACY as determined by HPLC was used as a covariate in the linear model to remove the small but significant indirect effects of scaling from the analysis.

\section{Results and Discussion}

GCA effects were significant and were larger than SCA effects for all traits examined with the exception of fruit size, for which SCA effects were larger (Table 2). In addition, significant genotype $\times$ year interactions were not present except for dates of first open flower, first ripe fruit, and the number of

Table 2. Mean squares, calculated additive genetic variance $\left(\sigma_{\mathrm{a}}{ }^{2}\right)$, and narrow-sense heritability $\left(h^{2}\right)$ estimates in 2005 to 2006 for phenological, vegetative, and fruit chemistry traits for 21 black raspberry families produced from an incomplete partial diallel mating scheme and grown in Corvallis, OR.

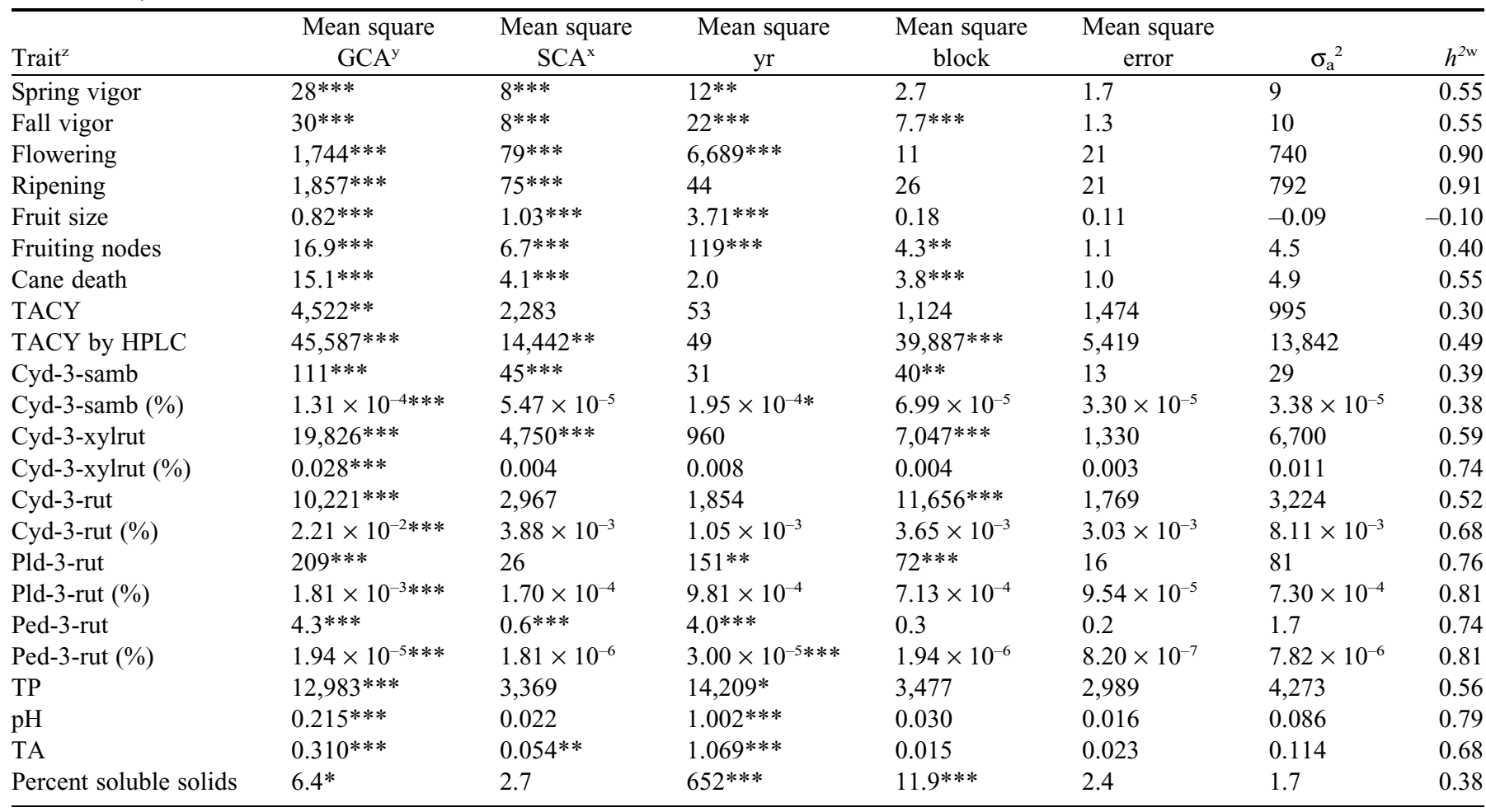

$\overline{\mathrm{z}} \mathrm{TACY}=$ total anthocyanin content by $\mathrm{pH}$ differential method; TACY by HPLC $=$ total anthocyanin content determined as the sum of anthocyanins detected by high-performance liquid chromatography; Cyd-3-samb = cyanidin-3-sambubioside; Cyd-3-xylrut $=$ cyanidin-3xylosylrutinoside; Cyd-3-rut = cyanidin-3-rutinoside; Pld-3-rut = pelargonidin-3-rutinoside; TP = total phenolics; anthocyanins and phenolics expressed as $\mathrm{mg} / 100 \mathrm{~mL}$ juice, TA (titratable acidity) expressed as citric acid equivalents ( $\mathrm{g} / 100 \mathrm{~g}$ of berries).

${ }^{\mathrm{y}} \mathrm{GCA}=$ general combining ability.

${ }^{\mathrm{x}} \mathrm{SCA}=$ specific combining ability.

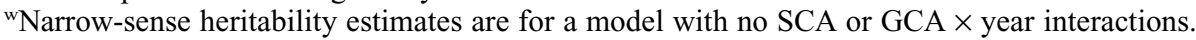

${ }^{*, * * * * * * *}$ Significant at $P \leq 0.05,0.01$, or 0.001 , respectively. 
fruiting laterals per node (data not shown). These cases are discussed subsequently; however, the lack of interactions for most traits suggest that selection for the best performers may be made fairly reliably based on a single season of observation, because the relative rankings of plants will not change much from year to year. Table 2 shows the mean squares and $h^{2}$ of the traits of interest. The $h^{2}$ of traits across years were calculated with year $\times$ GCA and year $\times$ SCA interactions excluded from the model.

For vigor, as measured in spring and fall, there was a slight but significant ( $P \leq 0.01$ for spring, $P \leq 0.001$ for fall) decline of $\approx 0.3$ from 2005 to 2006 , and values for spring and fall from within the same year were similar (data not shown). There may be a variety of reasons for this decline; however, increased disease pressure in the field is the most likely cause. The analysis of all families, including the parents 'Jewel' and 'Dundee', reveals that all five families with the parent NC 84-10-3 ranked highest for vigor in both seasons. Not surprisingly, NC 84-10-3 showed a significant and large GCA in the spring and fall (Table 3 ). The only other parent that showed a significant positive GCA for vigor was 'New Logan', although the effects were small in both seasons. 'Hanover', 'John Robertson', and 'Mac Black' all showed significant negative GCAs for vigor in spring and fall, whereas the negative GCA for 'Black Hawk' was significant in fall only. These negative GCA values ranged from -0.8 to -0.3 . 'Mac Black' had the highest negative GCA for spring vigor. Some of this effect could be the result of later budbreak, but it should not have an impact on vigor scored in late August that also had a large negative GCA. In 2005 and 2006, the cross 'Mac Black' $\times$ NC 84-10-3 showed a significant improvement in vigor scores from spring to fall. This is attributed to later spring budbreak resulting in lower spring vigor scores. Fall vigor scores for this family were high, however, and fell in a group with the other progenies of NC 84-10-3 as being the most vigorous. SCA effects were also significant for vigor in both seasons, but fell into patterns that could be predicted by one of their parents. Contrary to the observations of Ourecky and Slate (1966), hybrids involving $R$. leucodermis did not seem to be any more vigorous than pure $R$. occidentalis. Although the single most vigorous plant in the entire field came from the cross 'Mac Black' $\times R$. leucodermis, this was not a general trend. In spring, $R$. leucodermis had a slightly positive GCA and in fall, it had a slightly negative GCA; neither of these was statistically significant. At least two factors could explain this: 1) the pollen sample used for crosses involving $R$. leucodermis was a bulk pollen sample from several genotypes and not a single source or 2 ) the R. leucodermis material that Ourecky and Slate (1966) were working with may have been of a different provenance and their observations were made in the eastern United States, not in Oregon. The $h^{2}$ of vigor in spring and fall were moderate (0.55 for both).

Table 3. General combining ability (GCA) values for eight black raspberry parents used in diallel mating scheme in Corvallis, OR, in 2005 to 2006.

\begin{tabular}{|c|c|c|c|c|c|c|c|c|c|}
\hline Trait $^{z}$ & Black Hawk & Hanover & John Robertson & Mac Black & Munger & New Logan & NC 84-10-3 & R. leucodermis & Grand mean \\
\hline Spring vigor & -0.1 & $-0.4 * * *$ & $-0.5^{* * *}$ & $-0.8 * * *$ & 0.0 & $0.3^{* *}$ & $1.5 * * *$ & 0.1 & 4.7 \\
\hline Fall vigor & $-0.3 * *$ & $-0.4 * * *$ & $-0.5 * * *$ & $-0.4 * * *$ & -0.1 & $0.2^{*}$ & $1.7 * * *$ & -0.1 & 4.7 \\
\hline Flowering & 0.6 & $-2.3 * * *$ & -0.6 & $8.2 * * *$ & $-0.7 *$ & $-1.1 * *$ & $-3.2 * * *$ & -0.8 & 11 May \\
\hline Fruit size & 0.03 & $0.15 * * *$ & 0.0 & 0.02 & -0.01 & -0.03 & $-0.18 * * *$ & 0.02 & 1.41 \\
\hline Fruiting nodes & 0.1 & $0.3^{* * *}$ & $0.3 * * *$ & $-0.4 * * *$ & $-0.4 * * *$ & -0.1 & $0.3^{*}$ & -0.2 & 3.6 \\
\hline Cane death & 0.1 & 0.2 & 0.1 & 0.0 & $0.3 * * *$ & $0.4 * * *$ & $-1.0 * * *$ & -0.1 & 1.8 \\
\hline TACY by HPLC & $39.3 * *$ & -15.6 & $-73.7 * * *$ & 14.3 & -4.1 & -6.1 & $48.6 * *$ & -2.7 & 367.5 \\
\hline Cyd-3-samb & $1.4^{*}$ & -0.7 & $-3.1 * * *$ & 0.8 & $-1.1^{*}$ & $-1.3 *$ & $3.5^{* * *}$ & 0.4 & 10.8 \\
\hline Cyd-3-samb (\%) & -0.0 & -0.0 & -0.0 & 0.1 & $-0.2 *$ & $-0.3 * *$ & $0.4^{* *}$ & 0.2 & 3.6 \\
\hline Cyd-3-xylrut & $20.7 * * *$ & $-11.6^{*}$ & $-37.1 * * *$ & 5.5 & -8.2 & $-18.6^{* *}$ & $55.8 * * *$ & -6.5 & 136.7 \\
\hline Cyd-3-xylrut (\%) & 0.6 & -1.1 & $-1.8 *$ & 0.6 & -1.2 & $-4.0 * * *$ & $8.2 * * *$ & -1.3 & 41.5 \\
\hline Cyd-3-rut & $17.7 *$ & -5.1 & $-33.1 * * *$ & 11.8 & 4.0 & 11.9 & -8.5 & 1.3 & 196.7 \\
\hline Ped-3-rut (\%) & 0.0 & $0.0^{* \mathrm{y}}$ & 0.0 & $0.2 * * *$ & -0.0 & -0.0 & $-0.1 * *$ & -0.0 & 0.2 \\
\hline $\mathrm{TP}$ & 11.9 & 9.5 & $-40.8 * * *$ & $-21.0^{*}$ & 4.0 & 5.1 & $35.3 * *$ & -4.1 & 267.7 \\
\hline $\mathrm{pH}$ & 0.01 & $0.09 * * *$ & $-0.08 * * *$ & $-0.17 * * *$ & 0.02 & 0.02 & $0.10 * * *$ & 0.01 & 3.69 \\
\hline TA & 0.02 & $-0.07 * *$ & 0.02 & $0.22 * * *$ & $-0.06^{*}$ & -0.03 & -0.15 & 0.04 & 0.90 \\
\hline Percent soluble solids & -0.37 & 0.30 & -0.24 & $-0.95 * * *$ & 0.01 & 0.25 & $0.92 * *$ & 0.07 & 16.45 \\
\hline
\end{tabular}

$\overline{\text { zTACY }}=$ total anthocyanin content by $\mathrm{pH}$ differential method; TACY by HPLC $=$ total anthocyanin content determined as the sum of anthocyanins detected by high-performance liquid chromatography; Cyd-3-samb = cyanidin-3-sambubioside; Cyd-3-xylrut = cyanidin-3xylosylrutinoside; Cyd-3-rut = cyanidin-3-rutinoside; Pld-3-rut = pelargonidin-3-rutinoside; TP = total phenolics; anthocyanins and phenolics expressed as $\mathrm{mg} / 100 \mathrm{~mL}$ juice, TA (titratable acidity) expressed as citric acid equivalents ( $\mathrm{g} / 100 \mathrm{~g}$ of berries).

${ }^{y} P$ value statistically significant $(\mathrm{GCA}=0.04)$; however, errors resulting from peak integration at this low concentration may contribute to the variation.

${ }^{*, * * * * * *}$ Significant at $P \leq 0.05,0.01$, or 0.001 , respectively. 
There was considerable phenotypic variation in flowering and ripening times with dates of first flower stretching out over more than 4 weeks in 2005 and just over 3 weeks in 2006. Dates of first ripe fruit were similar in both years. The differences observed in date of first flower and flowering times between years are likely the result of differences in the weather. In 2005, April was warm, whereas May and early June were characterized by cooler, wetter conditions that prolonged bloom. The earliest genotypes began flowering 27 Apr., whereas the latest began flowering 30 May. In 2006, flowering did not begin until 5 May, whereas the latest genotypes began flowering on 28 May. In 2006, the unseasonably warm weather continued through the ripening period into late July. This response to weather conditions and the resulting genotype $\times$ year interaction was not entirely surprising. Finn et al. (2003) found that in 1997 , the date of first flowering in a group of $R$. leucodermis populations was spread over 2 weeks, whereas in 1996, it occurred over only $3 \mathrm{~d}$ and attributed this difference to weather conditions. In the present study, NC 84-10-3 had the largest negative GCA for flowering and ripening dates; on average, its progenies were the earliest to bloom and ripen fruit. Conversely, 'Mac Black' had the largest positive GCA for flowering and ripening, over $8 \mathrm{~d}$ in both cases. Between these extremes, 'Hanover', 'Munger', and 'New Logan' had significant negative GCAs for flowering and ripening dates, whereas 'John Robertson' also had a significant negative GCA for ripening time. Although SCA effects for these traits were also significant, $h^{2}$ for these traits was very high, over 0.90 , in the initial analysis (Table 2). Inclusion of SCA and GCA $\times$ year interactions lowered estimated $h^{2}$ of these traits only slightly, to 0.80 and 0.83 , respectively.

The SCA and GCA effects were significant for fruit size; however, SCA effects were slightly larger than GCA effects so calculated $h^{2}$ was negative (Table 2). 'Hanover' had a positive GCA for larger fruit size, whereas NC 84-10-3 had a negative GCA (Table $3)$. SCA for fruit size is summarized in Table 4 . The low $h^{2}$ of fruit size was somewhat surprising. Connor et al. (2005b) estimated $h^{2}$ of fruit size in red raspberry ( $R$. idaeus) from a factorial mating design using two methods and found $h^{2}$ to be moderately high across years ( 0.61 to 0.77$)$. In a comparison of all 26 families, strong trends in fruit size based on plant parentage are apparent. Progenies of 'Dundee' and NC 84-10-3 ranked among the lowest for fruit size. Although this is reflected in a significant negative GCA for NC 84-10-3, 'Dundee' was not included in the GCA/SCA analysis. The seven families with the largest fruit had either 'Black Hawk' or 'Mac Black' as parents. However, the cross 'Black Hawk' $\times$ 'Mac Black' had the smallest fruit of all 26 families and had severe sterility problems. Several plants of this combination not only were weak, but set only two or three drupelets per fruit. This result as well as the exclu- sion of progenies of 'Dundee' from the analysis may partly explain the low calculated $h^{2}$. Average fruit size ranged from $0.8 \mathrm{~g}$ to $3.4 \mathrm{~g}$ over both years with a mean of $1.5 \mathrm{~g}$ in 2005 and $1.4 \mathrm{~g}$ in 2006 (data not shown). This decline in fruit size is statistically significant and may be the result of increased disease stresses in 2006 or unseasonably warm temperatures in 2006 when there were $2 \mathrm{~d}$ in excess of $38^{\circ} \mathrm{C}$ less than 1 week before harvest began. Although temperatures moderated slightly afterward, daytime highs were consistently in excess of $32{ }^{\circ} \mathrm{C}$ throughout the harvest period.

The number of fruiting nodes per lateral had significant GCA and SCA effects (Table 2); however, GCA $\times$ year and $\mathrm{SCA} \times$ year interactions were also significant (data not shown). The $h^{2}$ for this trait was moderate when these interactions were not included (Table 2). However, because of the highly significant interactions with year, this source of variation needs to be given consideration. When GCA and SCA $\times$ year interactions were included in the model and this calculation, calculated $h^{2}$ dropped to 0.21 . The importance of this trait, along with the causes of the observed variability, are not well understood. Although it appears that there is some genetic control over this trait, environmental effects probably have a very large role as well. Strik et al. (1994) found that pruning had a significant effect on length of fruiting laterals and the number of fruit on each lateral. Strik et al. (1994) concluded that the number of laterals and fruit appeared to be the mode of observed yield compensation for differentially pruned plants. Pruning throughout the field in this experiment was consistent, suggesting that observed differences in this phenotype have more to do with expression of yield potential in healthy plants of which there are other components. In addition, plants infected by Verticillium wilt or viruses that may decrease yield potential could also be affecting the expression of this phenotype.

Table 4. Specific combining ability (SCA) and standard error for fruit size in 2005 to 2006 for 21 families produced from an incomplete partial diallel mating scheme among eight black raspberry genotypes and grown in Corvallis, OR.

\begin{tabular}{lcrrcc}
\hline Cross & Family & $\mathrm{n}^{\mathrm{Z}}$ & \multicolumn{1}{c}{ SCA } & \multicolumn{1}{c}{ SE } & $P$ \\
\hline Black Hawk $\times$ Hanover & 3012 & 61 & 0.30 & 0.04 & $<0.001$ \\
Black Hawk $\times$ John Robertson & 3013 & 60 & 0.15 & 0.04 & $<0.001$ \\
Mac Black $\times$ Black Hawk & 3024 & 15 & -0.54 & 0.06 & $<0.001$ \\
Black Hawk $\times$ Munger & 3014 & 62 & 0.09 & 0.04 & 0.02 \\
Black Hawk $\times$ New Logan & 3038 & 7 & 0.01 & 0.08 & 0.87 \\
Black Hawk $\times$ NC 84-10-3 & 3015 & 10 & -0.01 & 0.06 & 0.85 \\
Hanover $\times$ John Robertson & 3018 & 60 & -0.15 & 0.04 & $<0.001$ \\
Mac Black $\times$ Hanover & 3025 & 14 & 0.09 & 0.06 & 0.16 \\
Munger $\times$ Hanover & 3032 & 46 & -0.06 & 0.04 & 0.14 \\
New Logan $\times$ Hanover & 3039 & 46 & -0.16 & 0.04 & $<0.001$ \\
Mac Black $\times$ John Robertson & 3026 & 58 & 0.00 & 0.04 & 0.92 \\
Munger $\times$ John Robertson & 3034 & 54 & -0.02 & 0.04 & 0.65 \\
New Logan $\times$ John Robertson & 3040 & 53 & 0.08 & 0.04 & 0.05 \\
John Robertson $\times$ NC 84-10-3 & 3022 & 64 & -0.06 & 0.05 & 0.20 \\
John Robertson $\times$ Rubus leucodermis & 3023 & 45 & -0.01 & 0.04 & 0.83 \\
Mac Black $\times$ Munger & 3027 & 39 & 0.14 & 0.04 & $<0.001$ \\
Mac Black $\times$ New Logan & 3029 & 57 & 0.10 & 0.04 & 0.02 \\
Mac Black $\times$ NC 84-10-3 & 3028 & 16 & 0.07 & 0.06 & 0.21 \\
Mac Black $\times$ R. leucodermis & 3030 & 16 & 0.13 & 0.05 & 0.01 \\
New Logan $\times$ Munger & 3041 & 62 & -0.03 & 0.04 & 0.42 \\
Munger $\times$ R. leucodermis & 3036 & 50 & -0.12 & 0.04 & $<0.001$ \\
\hline
\end{tabular}

$\mathrm{z}_{\mathrm{n}}=$ number of plants sampled in fruit weight calculations for each cross. 
Disease incidence in the plot was evaluated in several ways. In 2005, all plants tested negative by ELISA for RBDV, TSV, and TomRSV. Leaf symptoms suggested the presence of other viruses in the field, and the presence of black raspberry necrosis virus (BRNV) was confirmed in at least a few plants; however, widespread testing for the presence of viruses other than the three tested by ELISA was not conducted. Powdery mildew infections occurred in the field in both years, but the only genotypes that persistently showed signs of infection had 'John Robertson' as a parent, so this trait was not included in the GCA/SCA analysis. Similarly, plants with Verticillium wilt were observed in both years. Disease severity and infection rates appeared to be greatest in genotypes with 'Dundee' as a parent; however, 'Dundee' and 'Jewel' were selectively removed from the design matrix for testing GCA and SCA effects. With the exception of the cross 'Dundee' $\times$ NC 84-10-3, which was high in vigor along with its other NC 84-10-3 halfsibs, the families having 'Dundee' as a parent ranked among the lowest in vigor and may be an indication of the pressure of Verticillium wilt on these families. However, it is difficult to make conclusions on susceptibility to Verticillium wilt without controlled inoculations and screenings, particularly without prior knowledge of occurrence and concentrations of the fungi in the field acting as inoculum.

Winter cane death can be a result of cold injury as well as BRNV, Verticillium wilt, or anthracnose infection that may weaken canes or kill them outright. Winter cane death scores in Spring 2006 and 2007 ranged from 0 to 5 with GCA and SCA effects being significant (Table 2 ). $h^{2}$ for this trait was moderate with progenies of $\mathrm{NC} 84-10-3$ having the least winter cane death and a large negative GCA effect (Table 3 ). A comparison of all 26 families shows that four of five families with NC 8410-3 as a parent had average scores below 1. Progenies of 'Munger' and 'New Logan' had more winter cane death than average (Table 3); of the 26 families, the 10 with the highest degree of winter cane death all had one or the other as a parent. The fact that the progenies of the wild parent from the Piedmont area of North Carolina showed the least amount of winter cane injury, particularly as compared with progenies of cultivars originating from much more cold-adapted climates, suggests that, in Oregon, this phenotype may have more to do with susceptibility to disease pressures than cold temperatures.

The juice from black raspberry populations in this study showed variation for TACY. Family means ranged from 117 $\mathrm{mg} / 100 \mathrm{~mL}$ ('Dundee' $\times R$. leucodermis) to $203 \mathrm{mg} / 100 \mathrm{~mL}$ ('Black Hawk' $\times$ NC 84-10-3) as measured by $\mathrm{pH}$ differential and $246.2 \mathrm{mg} / 100 \mathrm{~mL}$ ('Dundee' $\times R$. leucodermis) to 543.2 $\mathrm{mg} / 100 \mathrm{~mL}$ ('Black Hawk' $\times$ NC 84-10-3) by HPLC, and values did not vary significantly with year (Table 2 ). TACY measured by the $\mathrm{pH}$ differential method were lower than TACY by HPLC/DAD, but measurements were significantly correlated (Spearman rank order correlation $\mathrm{R}=0.68, P \leq 0.05$ ). GCA effects were significant, whereas SCA effects were large but not statistically significant $(P=0.11)$. Only one parent, 'John Robertson', had a significant and very large negative GCA ( -23.8 by $\mathrm{pH}$ differential and -73.7 by HPLC). NC 84-103 had a large positive GCA (17.4 by pH differential and 48.6 by HPLC, $P=0.05)$. The $h^{2}(0.30$, TACY obtained by $\mathrm{pH}$ differential) for this trait was moderately low. TACY by HPLC followed the same general pattern as measurements for $\mathrm{pH}$ differential (Table 3); however, larger differences were detected and there was greater statistical separation between families as well as parental GCA values with HPLC. This greater level of separation is the likely reason for the higher $h^{2}$ (0.49) of TACY by HPLC.

Six individual anthocyanins were detected in juice from the populations in this study (Fig. 1). Cyanidin-3-xylosylrutinoside and cyanidin-3-rutinoside were the major anthocyanins, comprising roughly $90 \%$ of the sum of the individual anthocyanins. Cyanidin-3-sambubioside and pelargonidin-3-rutinoside were found in much smaller quantities, each comprising roughly $1 \%$ to $5 \%$ of the TACY. Peonidin-3-rutinoside was less than $1 \%$ of the TACY. Cyanidin-3-glucoside was not quantified separately because it coeluted with cyanidin-3-xylosylrutinoside. Based on an extracted ion chromatogram of 449.2, minor amounts of cyanidin-3-glucoside were detected. The anthocyanin profile of most parents and progenies was similar to that of 'Munger' (Fig. 1). 'Jewel' showed a higher proportion of cyanidin-3xylosylrutinoside relative to cyanidin-3-rutinoside than 'Munger', but cyanidin-3-rutinoside was still the dominant pigment. In contrast, in NC 84-10-3 and most of its progenies, the proportions were reversed with higher amounts of cyanidin3-rutinoside than of cyanidin-3-xylosylrutinoside. This same pattern also appeared in three of 26 samples from progenies of R. leucodermis.

The identity of cyanidin-3-xylosylrutinoside as one of the dominant pigments was confirmed by UV-Vis absorption spectra. Figure 2 shows the UV-Vis absorption spectra of the peak identified as cyanidin-3-xylosylrutinoside from black raspberry overlaid with the UV-Vis absorption spectra of

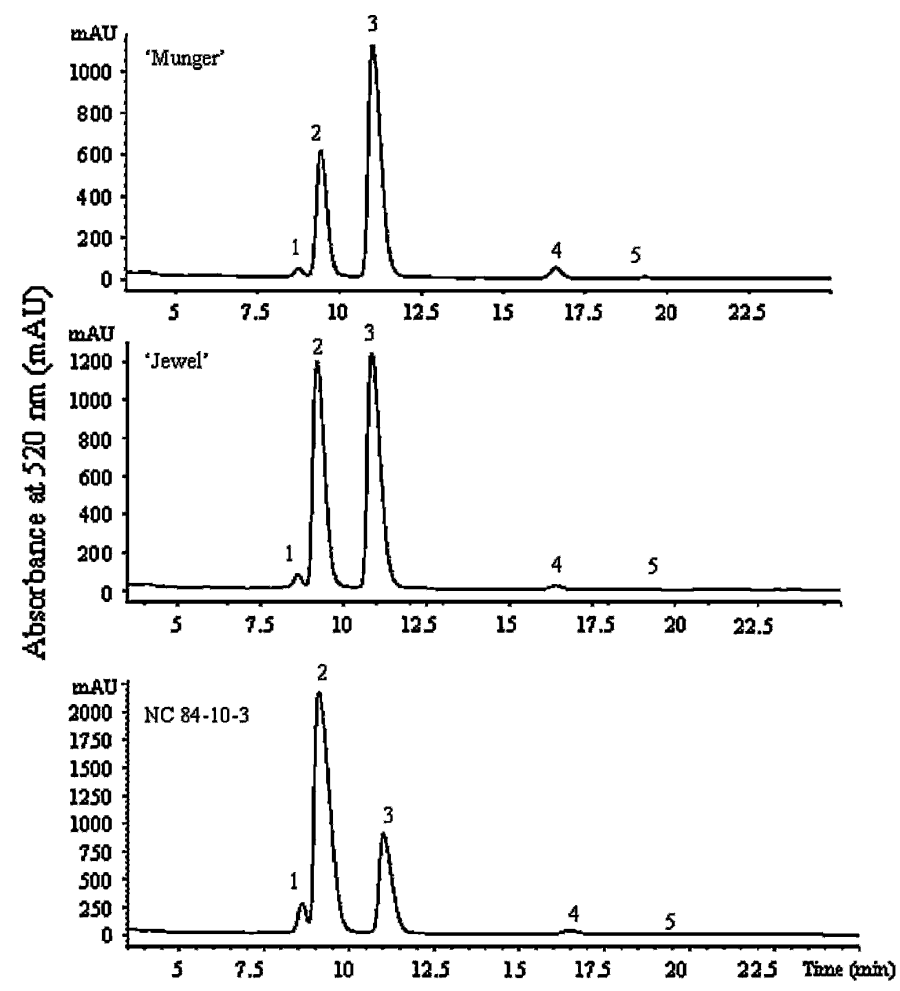

Fig. 1. Anthocyanin profiles for 'Munger', 'Jewel', and NC 84-10-3 black raspberry juice in 2005 from fruit harvested from plants grown in Corvallis, OR. Peak numbers are identified as follows [masses of molecular ions (M + $\mathbf{H})^{+}$and their fragments): (1) cyanidin-3-sambubioside (581, 287); (2) cyanidin-3-glucoside (minor) and cyanidin-3-xylosylrutinoside $(\mathbf{7 2 7}, 581$, 287); (3) cyanidin-3-rutinoside $(595,287)$; (4) pelargonidin-3-rutinoside $(\mathbf{5 8 0}, 271)$; and $(\mathbf{5})$ peonidin-3-rutinoside $(\mathbf{6 0 9}, 301)$. 


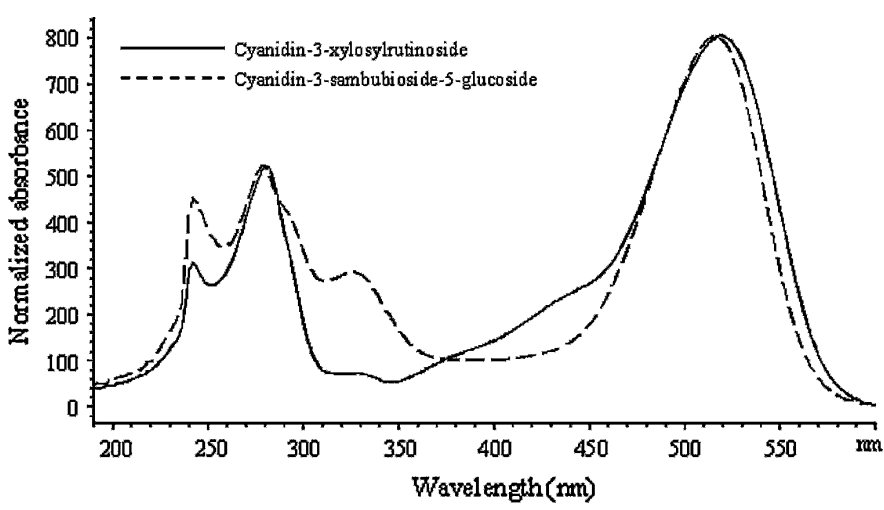

Fig. 2. Ultraviolet-visible spectra of cyanidin-3-xylosylrutinoside 'Mac Black' black raspberry overlaid with the spectra of cyanidin-3-sambubioside-5glucoside from elderberry (Lee and Finn, 2007) showing spectral difference in $E_{440} / E_{\lambda \max }$ separating 3-glucoside from 3,5-diglucoside.

cyanidin-3-sambubioside-5-glucoside from elderberry [Sambucus canadensis L. (Lee and Finn, 2007)]. The spectral differences between 3-glycosides and 3,5-diglycosides have been well established in the literature (Harborne, 1958; Hong and Wrolstad, 1990). Specifically, in the region of 400 to $460 \mathrm{~nm}$, the ratio traditionally expressed as $E_{440} / E_{\lambda \max }$ in 3-glycosides is roughly twice that observed in 3,5-diglycosides. The difference in shape of the two spectra can be clearly seen in Figure 2 and indicates that this anthocyanin is indeed cyanidin-3-xylosylrutinoside as reported by Hong and Wrolstad (1990) and Tian et al. (2006) rather than cyanidin-3-sambubioside-5-rhamnoside as postulated by $\mathrm{Wu}$ and Prior (2005).

For individual anthocyanins, block and year effects were significant indicating a significant degree of environmental variation; however, $h^{2}$ (greater than 0.39 , Table 2) was still moderate to high. $h^{2}$ of the total amount of individual anthocyanins ranged from 0.39 to 0.76 . Although the $h^{2}$ for TACY were somewhat lower $(0.49$ versus 0.74 as determined by HPLC) than that described by Connor et al. (2005a) for red raspberry, the estimates for individual anthocyanin components were much closer. The differences could be attributable, at least in part, to the degree of genetic variability in the populations because Connor et al. (2005a) found $h^{2}$ to be lower when they excluded a pigment-deficient parent from their analysis. It is also possible that within this population, TACY are more heavily influenced by environmental or nonadditive genetic factors such as epistasis than the individual anthocyanins.

In an attempt to characterize the anthocyanin profiles, the $h^{2}$ of the percentage of the TACY for each anthocyanin component was calculated from the variance components in the same manner as the other traits except with a covariate model. $h^{2}$ of the percentage of each anthocyanin in the profile were generally similar or slightly higher than $h^{2}$ for the total amount of the corresponding anthocyanin and ranged from 0.38 to 0.81 (Table $2)$. This is not surprising given the strong patterns with parentage observed in these families, particularly with respect to the two major anthocyanins (cyanidin-3-xylosylrutinoside and cyanidin-3-rutinoside).

$\mathrm{TP}$ in black raspberry juice from these populations also varied widely, with significant GCA but not SCA effects (Table 2). NC 84-10-3 had a high positive GCA, whereas 'John Robertson' and 'Mac Black' had high negative GCAs for TP. The cross 'Black Hawk' $\times$ 'Hanover' was the only cross for which there was a statistically significant SCA for TP. The $h^{2}$ (0.56) for this trait was moderate and higher than for TACY. This estimate is similar to, but slightly higher than, that found by Connor et al. (2005b) for red raspberry.

The TA and $\mathrm{pH}$ values ranged widely among populations and were strongly tied to parental genotype as shown by significant GCA values (Table 3). Although GCA and SCA effects were statistically important for TA, only GCA effects were statistically significant for $\mathrm{pH}$ (Table 2). 'Mac Black' as a parent had the largest effect on $\mathrm{pH}$ and TA with a positive GCA for TA. All other parents either had nonsignificant GCA effects or their GCA effect on TA was negative. NC 84-10-3 had the largest negative GCA for TA (Table 3). This trait seems to be somewhat correlated to ripening times and may be an indication of stage of fruit ripeness as TA decreases and soluble solids increase during fruit ripening. Although every possible effort was made to pick fruit that were fully ripe, there was a tendency toward higher acidity in fruit of later ripening genotypes than of earlier ripening genotypes. Calculated $h^{2}$ for $\mathrm{pH}$ and TA were high ( 0.79 and 0.68 , respectively).

Phenotypic variation in percent soluble solids was also considerable with significant block and year effects (Table 2). Mean soluble solids in 2005 were 14.4\%, whereas in 2006, they were $18.4 \%$ (data not shown). This may be related to a number of causal factors. The drop in fruit size previously noted from 2005 to 2006 could result in a higher concentration of sugars. It could also be that this was the result of weather that was generally much warmer and drier during fruit ripening in 2006 than in 2005. Temperatures during the fruit ripening period were consistently in excess of $32^{\circ} \mathrm{C}$ and on $2 \mathrm{~d}$ exceeded $38^{\circ} \mathrm{C}$. The $h^{2}$ for percent soluble solids was moderately low $\left(h^{2}=\right.$ 0.38). Parents with significant GCA effects were limited to the earliest ripening, NC 84-10-3, which had a positive GCA of 0.92 , and the latest ripening, 'Mac Black,' which had a negative GCA of -0.95 (Table 3). SCA effects were not significant.

To make progress from selection in a breeding program, there are two important prerequisites, adequate variation and sufficient heritability of that variation. Heritability directly affects the expected gain from every round of selection, and variation must be present for selection to take place. Although heritability was generally moderate to high for the traits of interest, significance of GCA values indicates that most of the heritable additive genetic variation within this set of parents was found in three clones: 'John Robertson', 'Mac Black', and NC 84-10-3. Lack of genetic variation in black raspberry has been noted as a limiting factor in breeding new cultivars by many since the first half of the 20th century (Drain, 1952, 1956; Ourecky, 1975; Slate, 1944; Weber, 2003); however, none of these studies investigated fruit chemistry traits. It may be easy to dismiss $R$. leucodermis as a source of variation in breeding-improved black raspberry cultivars based on these results because the only significant GCA values recorded for traits of interest were for one of the minor individual anthocyanins (pelargonidin-3-rutinoside; Table 3 ). The use of a bulk pollen sample from $R$. leucodermis would have the effect of lowering $h^{2}$ because it results in more variability in the resulting progeny, thereby lowering the statistical significance of the GCA effects for crosses involving $R$. leucodermis. Finn et al. (2003) found significant phenotypic variation in populations of $R$. leucodermis from throughout the Pacific northwestern United States for many of the same traits examined in this study so use of germplasm from this species may well present a source of variability for breeding. 
For TACY, estimated $h^{2}$ was relatively low and greater progress might be made by focusing on increasing the amount of the individual anthocyanins for which estimated $h^{2}$ was higher. The difficulty here is that two anthocyanins (cyanidin-3xylosylrutinoside and cyanidin-3-rutinoside) comprise $\approx 90 \%$ of the TACY. Samples from progenies of 'Jewel', NC 84-10-3 as well as from $R$. leucodermis suggest that it should be possible to bring the ratio of these two major anthocyanins close to $1: 1$. Because there was little variability in the original anthocyanin profiles and because NC 84-10-3 had such a different profile, a better understanding of the genetics controlling this difference may be needed before clear conclusions are made. Additionally, samples for fruit chemistry traits were bulked by family within blocks, thereby masking within-plot variability and making it impossible to determine segregation ratios, if present, among progenies. Harborne and Hall (1964) concluded that the presence of branched trisaccharides on the anthocyanin aglycones was not the result of specific genes for their formation, but instead was likely the result of the presence of genes for individual sugars being present together (e.g., genes for xylose in addition to glucose give the disaccharide sambubioside and genes for rhamnose along with glucose give the disaccharide rutinoside). When the two are present together, the trisaccharide xylosylrutinoside is also formed without the need for a special trisaccharide-forming enzyme. Our results support a genetic influence on the concentration of xylosylrutinoside relative to rutinoside and sambubioside residues on the cyanidin. NC 84-10-3, which has a high positive GCA for cyanidin3-xylosylrutinoside, also has a slightly positive although nonstatistically significant GCA for cyanidin-3-sambubioside and a statistically significant positive GCA for percent cyanidin-3sambubioside, the other anthocyanin containing a xylose. This may be the result of an enzyme catalyzing the formation of xylosylrutinoside or possibly some other mechanism leading to higher amounts of xylose present during anthocyanin formation, resulting in a greater proportion of xylose-conjugated anthocyanins. Regardless of mechanism, heritable variation for the two major anthocyanins as well as the minor anthocyanins is significant, suggesting that it should be possible to breed and select for certain anthocyanin profiles.

It is interesting to note that 'John Robertson' and NC 84-103 , which contained much of the variability found in our study, are wild collected genotypes from near the edge of the native range for $R$. occidentalis. The origin of 'Mac Black' is unknown; however, some have suggested that its pedigree includes a species other than $R$. occidentalis, most likely $R$. idaeus (E. Makielski, personal communication). These observations suggest that variability may well be found from outside the current germplasm pool by surveying wild populations and perhaps other species.

NC 84-10-3 was found to be a particularly valuable parent not only for its high anthocyanins and phenolics, but also for high vigor and resistance to disease symptoms. However, its progenies had the smallest fruit size and the earliest bloom times. Although fruit size may not be too important for the commercial processing industry if yields can be maintained, 'Munger' has problems setting fruit in cool, wet, spring weather and an earlier bloom date may not be desirable for the processed market because of this (Finn et al., 2003). Some of these issues may be negated by using 'Mac Black' to delay bloom and largefruited cultivars such as 'Jewel' in crosses with NC 84-10-3. As a result of the presence of strong SCA effects, however, it may be more difficult to select and breed for larger fruit size. Moderate to high estimates of fruit size $h^{2}$ in red raspberry suggest that this might be possible in black raspberry; perhaps if the surveyed population was more diverse, there would be stronger GCA effects for this trait.

Despite the apparent drawbacks of NC 84-10-3, the use of this and perhaps other wild germplasms could bring tremendous benefit toward improving adaptability of cultivars. Although many cultivars originating in the late 1800 s and early 1900 s are reputed to have been discovered as chance or wild seedlings, they were selected for fruit quality traits that may have led, unknowingly, to the selection of plants that were feral and closely related to other cultivars. Thus, incorporation of "wild" germplasm into cultivar material historically has relied primarily on selecting first for productivity and fruit quality (large size and firmness). This strategy may be a good one, but it should be combined with careful consideration for the presence of other traits as well and perhaps in combination with molecular data to gauge genetic distance from existing elite germplasm. An alternative and perhaps more effective strategy would be to select first for adaptability and disease resistance in wild germplasm and cross this with elite material of high fruit quality, selecting for desired gains in the recombinants through recurrent phenotypic selection. Because most cultivars are either selections from the wild or are only two or three generations removed from wild ancestors, it should be less difficult to incorporate new wild germplasm into black raspberry and obtain commercially viable cultivars than it would be if the germplasm was more developed such as in other small fruit crops.

\section{Literature Cited}

Barritt, B. and L.C. Torre. 1973. Cellulose thin-layer chromatographic separation of Rubus fruit anthocyanins. J. Chromatogr. 75:151-155. Connor, A.M., T.K. McGhie, M.J. Stephens, H.K. Hall, and P.A. Alspach. 2005a. Variation and heritability estimates of anthocyanins and their relationship to antioxidant activity in a red raspberry factorial mating design. J. Amer. Soc. Hort. Sci. 130:534-542.

Connor, A.M., M.J. Stephens, H.K. Hall, and P.A. Alspach. 2005b. Variation and heritabilities of antioxidant activity and total phenolic content estimated from a red raspberry factorial experiment. J. Amer. Soc. Hort. Sci. 130:403-411.

Drain, B.D. 1952. Some inheritance data with black raspberries. Proc. Amer. Soc. Hort. Sci. 60:231-234.

Drain, B.D. 1956. Inheritance in black raspberry species. Proc. Amer. Soc. Hort. Sci. 68:169-170.

Finn, C.E., K. Wennstrom, J. Link, and J. Ridout. 2003. Evaluation of Rubus leucodermis populations from the Pacific Northwest. HortScience 38:1169-1172.

Galletta, G.J., J.L. Maas, and J.M. Enns. 1998. 'Earlysweet' black raspberry. Fruit Var. J. 52:123.

Geleta, L.F. and M.T. Labuschagne. 2006. Combining ability and heritability for vitamin $\mathrm{C}$ and total soluble solids in pepper (Capsicum annum L.). J. Sci. Food Agr. 86:1317-1320.

Griffing, B. 1956. Concept of general and specific combining ability in relation to diallel crossing systems. Aust. J. Biol. Sci. 9:463-493.

Halgren, A., I.E. Tzanetakis, and R.R. Martin. 2007. Identification, characterization and detection of Black raspberry necrosis virus. Phytopathology 97:44-50.

Harborne, J.B. 1958. Spectral methods of characterizing anthocyanins. Biochem. J. 70:22-28.

Harborne, J.B. and E. Hall. 1964. Plant polyphenols-XIII. Systematic distribution and origin of anthocyanins containing branched trisaccharides. Phytochemistry 3:453-463.

Hedrick, U.P. 1925. The small fruits of New York. New York State Agr. Expt. Sta. J.B. Lyon, Albany, NY. 
Hong, V. and R.E. Wrolstad. 1990. Use of HPLC separation/photodiode array detection for characterization of anthocyanins. J. Agr. Food Chem. 38:708-715.

Jennings, D.L. 1988. Raspberries and blackberries: Their breeding, diseases and growth. Academic Press, San Diego, CA.

Kempthorne, O. and R.N. Curnow. 1961. The partial diallel cross. Biometrics 17:229-250.

Kuhlman, G.W. and D.C. Mumford. 1949. Cost of producing black raspberries for processing in the Willamette Valley, Oregon. Oregon State College Agr. Expt. Sta. Bul. 473.

Lee, F.A. and G.L. Slate. 1954. Chemical composition and freezing adaptability of raspberries. New York State Agr. Expt. Sta. Bul. No. 761.

Lee, J., R.W. Durst, and R.E. Wrolstad. 2005. Determination of total monomeric anthocyanin pigment content of fruit juices, beverages, natural colorants, and wines by the $\mathrm{pH}$ differential method: Collaborative study. J. AOAC Int. 88:1269-1278.

Lee, J. and C.E. Finn. 2007. Anthocyanins and other polyphenolics in American elderberry (Sambucus canadensis) and European elderberry ( $S$. nigra) cultivars. J. Sci. Food Agr. 87:2665-2675.

Moyer, R.A., K.E. Hummer, C.E. Finn, B. Frei, and R.E. Wrolstad. 2002. Anthocyanins, phenolics, and antioxidant capacity in diverse small fruits: Vaccinium, Rubus, and Ribes. J. Agr. Food Chem. 50:519-525. Nybom, H. and B.A. Schaal. 1990. DNA 'fingerprints' reveal genotypic distributions in natural populations of blackberries and raspberries (Rubus, Rosaceae). Amer. J. Bot. 77:883-888.

Nybom, N. 1968. Cellulose thin layers for anthocyanin analysis with special reference to the anthocyanins of black raspberries. J. Chromatogr. 38:382-387.

Ourecky, D.K. 1975. Brambles, p. 98-129. In: Janick, J. and J.N. Moore (eds.). Advances in fruit breeding. Purdue University Press, West Lafayette, IN.

Ourecky, D.K. and G.L. Slate. 1966. Hybrid vigor in Rubus occidentalis $\times$ Rubus leucodermis seedlings. Proc. 17th Intl. Hort. Congr. 1:277 (abstr.)
Slate, G.L. 1944. Methods and problems in raspberry breeding. Proc Amer. Soc. Hort. Sci. 45:255-258.

Slate, G.L. and L.G. Klein. 1952. Black raspberry breeding. Proc. Amer. Soc. Hort. Sci. 59:266-268.

Strik, B.C., H. Cahn, N. Bell, and J. DeFrancesco. 1994. Caneberry research at North Willamette Research \& Extension Center-An update. Proc. Oregon Hort. Soc. 85:141-149.

Tian, Q., M.M. Giusti, G.D. Stoner, and S.J. Schwartz. 2006. Characterization of a new anthocyanin in black raspberries (Rubus occidentalis) by liquid chromatography electrospray ionization tandem mass spectrometry. Food Chem. 94:465-468.

Torre, L.C. and B.H. Barritt. 1977. Quantitative evaluation of Rubus fruit anthocyanin pigments. J. Food Sci. 42:488-490.

U.S. Department of Agriculture. 2007a. Oregon berry production. Press release 26 Jan. 2007. U.S. Dept. Agr., Natl. Agr. Stat. Serv., Oregon Field Office, Portland, OR.

U.S. Department of Agriculture. 2007b. NC 84-10-3. Germplasm Resources Information Network (GRIN). 28 Jan. 2008. <http:// www.ars-grin.gov/cgi-bin/npgs/acc/search.pl?accid=\%20PI+553755>.

Wang, S.Y. and H. Lin. 2000. Antioxidant activity in fruits and leaves of blackberry, raspberry and strawberry varies with cultivar and developmental stage. J. Agr. Food Chem. 48:140-146.

Waterhouse, A.L. 2002. Unit I1.1: Polyphenolics: Determination of total phenolics, p. 1-4. In: Wrolstad, R.E. (ed.). Current protocols in food analytical chemistry. Wiley, Hoboken, NJ.

Weber, C.A. 2003. Genetic diversity in black raspberry detected by RAPD markers. HortScience 38:269-272.

Wu, H.X. and A.C. Matheson. 2000. Analysis of half-diallel mating design with missing crosses: Theory and SAS program for testing and estimating GCA and SCA effects. Silvae Genet. 50:265271.

$\mathrm{Wu}, \mathrm{X}$. and R.L. Prior. 2005. Systematic identification and characterization of anthocyanins by HPLC-ESI-MS/MS in common foods in the United States: Fruits and berries. J. Agr. Food Chem. 53:25892599. 